\title{
Evaluation of Clinical Profile of Fever with Thrombocytopenia in Patients Attending GIMSR, Visakhapatnam
}

\author{
Mudunuri Sitarama Lakshmi ${ }^{1}$, Gandi Srinivasa Rao $^{2}$ \\ ${ }^{1}$ Assistant Professor, Department of General Medicine, Gitam Institute of Medical Sciences and Research, Rushikonda, \\ Visakhapatnam, ${ }^{2}$ Assistant Professor, Department of General Medicine, Gitam Institute of Medical Sciences and Research, \\ Rushikonda, Visakhapatnam, India
}

Corresponding author: Gandi Srinivasa Rao, Assistant Professor, Dept of General Medicine, Gitam Institute of Medical Sciences and Research, Rushikonda, Visakhapatnam, India

DOI: http://dx.doi.org/10.21276/ijcmsr.2020.5.1.24

BY-NC-ND

How to cite this article: Mudunuri Sitarama Lakshmi, Gandi Srinivasa Rao. Evaluation of clinical profile of fever with thrombocytopenia in patients attending GIMSR, Visakhapatnam. International Journal of Contemporary Medicine Surgery and Radiology. 2020;5(1):A102-A106.

\section{A B S T R A C T}

Introduction: Fever has been recognized as a cardinal manifestation of disease since ancient times, as recorded by ancient scholars like Hippocrates. Infections like dengue, leptospirosis, malaria, typhoid, military TB, HIV, septicemia are some of the common causes of fever with thrombocytopenia. Study aimed to evaluate clinical profile of fever with thrombocytopenia in patients attending GIMSR, Visakhapatnam.

Material and Methods: Patients with fever with thrombocytopenia attending to (GIMSR) GITAMS Medical college during the period from July 2018 to June 2019 were studied. 100 patients presenting with fever with thrombocytopenia were taken up for study. Age and gender distribution, duration of fever, clinical features, platelet counts, bleeding manifestations, liver function tests and presence of various etiologies was studied.

Results: A total of 100 patients were studied. The patient age ranged from 14 years to 67 years and the mean age was 33.38 years $(S D=14.19)$ and the male : female ratio was $1.44: 1$. The febrile illness with thrombocytopenia had maximum occurrence in the third (32\%). The four diseases which contributed mainly to febrile thrombocytopenia in our study were acute viral fever (34\%), Dengue (29\%), Leptospirosis (13\%) and Malaria (10\%). The duration of fever ranged from 1-20 days with mean duration of 6.05 days and $92 \%$ of them had duration of $<10$ days. Headache was the most common symptom other than fever in the present study. Derangement of LFT was also observed in most of the cases.

Conclusion: Febrile illness patients should be investigated for platelet count irrespective of bleeding manifestations. Strong probability of dengue fever or other common causes like viral fever and leptospirosis should be kept in mind in any case of fever and thrombocytopenia as decreased platelet count could be severe without external manifestation and could be an indicator of bad prognosis and require early platelet transfusion.

Keywords: Fever, Thrombocytopenia, Dengue Fever, Leptospirosis

\section{INTRODUCTION}

Fever has been recognized as a cardinal manifestation of disease since ancient times, as recorded by ancient scholars like Hippocrates. ${ }^{1}$ Seen first as a disease but later recognized as an accompaniment to a variety of disease entities; fever is an easily noted and reliable marker of illness. ${ }^{2}$

Normal body temperature displays a diurnal pattern with lower values in the early morning hours and higher values in the afternoon. Normal ranges are between $36.5^{\circ} \mathrm{C}$ and $37.5^{\circ} \mathrm{C}\left(97.7^{\circ} \mathrm{F}\right.$ and $\left.99.5^{\circ} \mathrm{F}\right)$. Fever is superimposed on this pattern and thus temperatures are usually greatest in the afternoon and evening.

Fever is defined as an elevation of the body temperature above normal circadian range as a result of change in the thermoregulatory center located in the anterior hypothalamus. An $\mathrm{AM}$ temperature of $>37.2^{\circ} \mathrm{C}\left(98.9^{\circ} \mathrm{F}\right)$ or a P.M. temperature of $>37.7^{\circ} \mathrm{C}\left(99.9^{\circ} \mathrm{F}\right)$ would define fever. ${ }^{3}$
Many infections can have significant thrombocytopenia and Malaria is one such infection. It is endemic throughout most of the tropics and is common in India as well. WHO states that more than 207 million developed symptomatic malaria in 2012. ${ }^{4}$

Physicians use fever as a reliable guide to the presence of disease and the response of disease to therapy. It is in the diagnosis of febrile illness that the science and art of medicine come together. ${ }^{5}$

It is well known fact in medicine that one can diagnose a disease only when one is aware of the disease and looks for it. Thrombocytopenia was often missed, because it was not often looked for and the required investigation was not asked for. Now with increasing awareness of the association of thrombocytopenia with various illnesses especially with febrile illness, this entity is now viewed with due regards. Though thrombocytopenia is encountered in various diseases, it is fortunate that potentially fatal bleeding due to 
thrombocytopenia is rare. ${ }^{6}$

The causes of thrombocytopenia are impaired platelet production, accelerated platelet destruction or dilution and/ or splenic sequestration. ${ }^{7}$

Even though there is no absolute relation between platelet counts and bleeding, certain broad generalizations can be made, with counts less than $10,000 / \mu 1$, bleeding is usual and may be severe. ${ }^{8}$

Thrombocytopenia correlates inversely with mortality and morbidity in various febrile illnesses, and serial monitoring of platelet counts has prognostic value. This highlights the importance of thrombocytopenia in various febrile disorders. ${ }^{9}$ Platelets play a central role in normal haemostasis and therefore also in thrombosis. Thrombocytopenia is characterized by bleeding most often from small vessels. This can manifest as petechiae over the skin, hemorrhages from mucosa of gastrointestinal and genitourinary tract. Intracranial haemorrhage is a dangerous consequence in thrombocytopenic patients.

Thrombocytopenia is defined as platelet count $<1,50,000 / \mu \mathrm{L}$. This is due to decreased production, increased destruction (immunogenic and non-immunogenic), and increased sequestration in spleen. Of these, infections is one of the commonest cause of thrombocytopenia. ${ }^{10,11}$

Infections like dengue, leptospirosis, malaria, typhoid, military TB, HIV, septicemia are some of the common causes of fever with thrombocytopenia.

Therefore a well organized systematic approach that is carried out with an awareness of causes of fever with thrombocytopenia narrows the differential diagnosis of the clinical entity and brings out diagnosis.

Study aimed to evaluate clinical profile of fever with thrombocytopenia in patients attending GIMSR, Visakhapatnam.

\section{MATERIAL AND METHODS}

Before stating the study, permission was taken from the Institutional Ethical Committee and Informed consent was taken from all patients included in the study.

Patients with fever with thrombocytopenia attending GIMSR Medical College during period of one year from July 2018 to June 2019 were taken into the study. 100 patients, selected by Simple random sampling, presenting with fever with thrombocytopenia were taken up for the study.

\section{Inclusion criteria}

Age from 14-70 years

Both genders

The patients presenting with fever $<2$ weeks duration

Patients admitted with fever and found to have thrombocytopenia, that is platelet count $<1.5$ lakhs were included in the study

\section{Exclusion criteria}

Age below 14 years and above 70 years

Patients with prolonged fever $>2$ weeks duration

Patients with fever and no thrombocytopenia

Patients with thrombocytopenia without fever

Once the patients with fever and thrombocytopenia were admitted, a careful history was recorded, and general physical examination and detailed examination of various systems was done. Routine investigation were done. The specific and special investigations were done as and when indicated. In those patients where a final definite diagnosis was reached, were treated for the disease and platelet counts were repeated. Details of history, general physical examination and laboratory investigation reports were noted down from time to time.

The diagnostic work up of patients with fever and thrombocytopenia was done including battery of investigations such as biochemical tests, hemograms, peripheral smear examination, QBC for Malarial parasite, WIDAL test, for dengue fever, IgM ELISA was done, Leptospiral antibodies test. Also Blood cultures were done in some cases.

\section{RESULTS}

The present study includes 100 patients who were admitted for acute febrile illness with thrombocytopenia in GIMSR, Visakhapatnam, between July 2018 to June 2019.

Males were more commonly involved than females in all age groups in the present study. The male: female ratio was 1.44:1 (table-1).

The patient age ranged from 14 years to 67 years and the mean age was 33.38 years $(\mathrm{SD}=14.19$ years $)$. The febrile illness with thrombocytopenia had maximum occurrence in the age group of third decade (32\%) followed by second decade $(23 \%)$ and was evenly distributed in the fourth and sixth decades having $19 \%$ and $16 \%$ patients respectively.

were Acute viral fever (34\%), Dengue (29\%), Leptospirosis (13\%) and Malaria (10\%). Acute febrile illness with thrombocytopenia due to above causes occurred maximum in second and third decades (table-2).

The duration of fever in the present study ranged from 1-20 days with mean duration of 6.05 days ( $\mathrm{SD}=3$ days). In $92 \%$ of the cases the duration was $<10$ days.

Headache was the most common symptom other than fever (32\%) in the present study. Other prominent symptoms in the descending order of frequency were myalgia (31\%), vomiting (27\%), joint pain (10\%) pain abdomen (6\%) and altered sensorium in (1\%) cases (table-3).

Hepatosplenomegaly contributed to major signs in the present study (21-24\%). Petechiae and conjunctival hemorrhage were seen in $20 \%$ cases, followed by jaundice (17\%) cases.

In the present study platelet count varied from 10,000 to 1 lakh/cumm. The platelet count for the patients with bleeding episodes ranged from 18000 to 40000 /cumm in the present study (table-4).

\begin{tabular}{|l|c|c|c|}
\hline Age (in years) & Males $(\mathbf{n = 5 9 )}$ & Females $(\mathbf{n = 4 1 )}$ & Total (\%) \\
\hline $14-20$ & 4 & 9 & 13 \\
\hline $21-30$ & 20 & 12 & 32 \\
\hline $31-40$ & 10 & 9 & 19 \\
\hline $41-50$ & 7 & 1 & 8 \\
\hline $51-60$ & 8 & 8 & 16 \\
\hline $61-70$ & 0 & 2 & 2 \\
\hline Total & 49 & 41 & $100(100 \%)$ \\
\hline \multicolumn{4}{|r}{ Table-1: Age and gender distribution in present study } \\
\hline
\end{tabular}




\begin{tabular}{|l|c|c|c|c|}
\hline Age (in years) & Dengue & Viral fever & Leptospirosis & Malaria \\
\hline $14-20$ & 7 & 10 & 2 & 3 \\
\hline $21-30$ & 9 & 16 & 4 & 3 \\
\hline $31-40$ & 7 & 4 & 4 & 3 \\
\hline $41-50$ & 3 & 0 & 1 & 0 \\
\hline $51-60$ & 2 & 4 & 0 & 0 \\
\hline $61-70$ & 1 & 0 & $13(13 \%)$ & $10(10 \%)$ \\
\hline Total & $29(29 \%)$ & $34(34 \%)$ & \\
\hline \multicolumn{7}{r|}{ Table-2: Age distribution for various etiologies } \\
\hline
\end{tabular}

\begin{tabular}{|l|c|c|}
\hline Days & Number of days & Percent (\%) \\
\hline $1-5$ & 55 & $35 \%$ \\
\hline $6-10$ & 37 & $6 \%$ \\
\hline $11-15$ & 6 & $2 \%$ \\
\hline$>15$ & 2 & $100 \%$ \\
\hline Total & 100 & \\
\hline \multicolumn{2}{|c|}{ Table-3: Duration of fever at the time of presentation } \\
\hline
\end{tabular}

\begin{tabular}{|l|c|c|}
\hline Platelet count/cumm & No. of patients & Percent (\%) \\
\hline $10001-20000$ & 5 & $20 \%$ \\
\hline $20001-40000$ & 20 & $18 \%$ \\
\hline $40001-60000$ & 18 & $27 \%$ \\
\hline $60001-80000$ & 27 & $30 \%$ \\
\hline $80001-100000$ & 30 & $100 \%$ \\
\hline Total & 100 & \\
\hline \multicolumn{2}{|c|}{ Table-4: Platelet count in present study } \\
\hline
\end{tabular}

\begin{tabular}{|l|c|c|c|c|}
\hline Platelet count & Dengue & Viral fever & Leptospirosis & Malaria \\
\hline $10000-20000$ & 5 & 1 & 0 & 0 \\
\hline $20000-40000$ & 13 & 5 & 1 & 0 \\
\hline $40000-60000$ & 4 & 4 & 6 & 0 \\
\hline $60000-80000$ & 3 & 16 & 3 & 4 \\
\hline $80000-100000$ & 4 & 8 & 13 & 10 \\
\hline Total (86) & $29 \quad 34$ & \\
\hline \multicolumn{2}{|r}{} \\
\hline
\end{tabular}

\begin{tabular}{|l|c|c|c|c|c|}
\hline Site of bleeding & $<\mathbf{2 0 0 0 0}$ & $\mathbf{2 0 0 0 0 - 4 0 0 0 0}$ & $\mathbf{4 0 0 0 0 - 6 0 0 0 0}$ & $\mathbf{6 0 0 0 0 - 8 0 0 0 0}$ & $\mathbf{8 0 0 0 0 - 1 0 0 0 0 0}$ \\
\hline Petechiae & 5 & 10 & 0 & 1 & 0 \\
\hline Gum bleeding & 2 & 3 & 0 & 1 & 0 \\
\hline Conjunctival haemorrhage & 0 & 1 & 2 & 0 & 1 \\
\hline Petechiae+gum bleeding & 2 & 2 & 0 & 1 & 0 \\
\hline Petechiae+epistaxis & 0 & 1 & 0 & 0 & 0 \\
\hline Malena & 0 & 1 & 0 & 0 & 0 \\
\hline Petechiae+conjunctival Hg & 0 & 1 & 0 & 0 & 0 \\
\hline \multicolumn{7}{|r|}{ Table-6: Bleeding manifestation and platelet count } \\
\hline
\end{tabular}

\begin{tabular}{|c|c|c|c|c|c|c|c|c|c|c|c|c|}
\hline \multirow[t]{2}{*}{ LFT } & \multicolumn{3}{|c|}{ Viral fever } & \multicolumn{3}{|c|}{ Dengue } & \multicolumn{3}{|c|}{ Leptospirosis } & \multicolumn{3}{|c|}{ Malaria } \\
\hline & 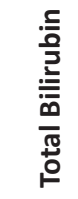 & 占 & 占 & 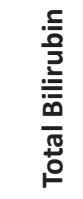 & 占 & 占 & 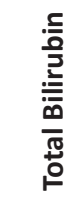 & 占 & 占 & 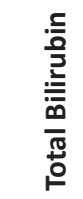 & 占 & 占 \\
\hline Normal & 25 & 21 & 23 & 12 & 10 & 9 & 3 & 2 & 2 & 7 & 7 & 8 \\
\hline Abnormal & 9 & 13 & 11 & 17 & 19 & 20 & 10 & 11 & 11 & 3 & 3 & 2 \\
\hline
\end{tabular}




\begin{tabular}{|c|c|c|c|c|c|}
\hline Etiology & Nair et $\mathrm{al}^{14}$ & Lakum et al $^{6}$ & Dash et $\mathrm{al}^{13}$ & Raiker et al ${ }^{12}$ & Present study \\
\hline Dengue & $13.8 \%$ & $35.4 \%$ & $20 \%$ & $52 \%$ & $29 \%$ \\
\hline Malaria & $9.2 \%$ & $46.8 \%$ & $45 \%$ & $45 \%$ & $10 \%$ \\
\hline Enteric fever & $14.7 \%$ & $4.6 \%$ & $10 \%$ & $3 \%$ & $1 \%$ \\
\hline Leptospirosis & - & - & $2 \%$ & - & $13 \%$ \\
\hline Septicaemia & $26.6 \%$ & $7.8 \%$ & $21 \%$ & - & $13 \%$ \\
\hline Viral Fever & $18.3 \%$ & - & - & - & $34 \%$ \\
\hline
\end{tabular}

Total platelet count varied according to the etiology. Dengue fever caused severe thrombocytopenia. Out of 29 cases of dengue fever $17.24 \%$ had platelet count <20000, $44.83 \%$ had platelet count in the range of 20001-40000/cumm. Of 34 cases of Viral fever, $2.94 \%$ had severe thrombocytopenia $<20000 /$ cumm, $14.71 \%$ had counts in the range of 2000 $40000,82.35 \%$ had platelet counts of $>40000 /$ cumm. In Leptospirosis $7.69 \%$ of patient had platelets in the range of $2000-40000,92.31 \%$ of patients had plateletcount of $>40000 /$ cumm. In Malaria none had <40,000/cumm. This showed that severe thrombocytopenia occurred more in patients with dengue fever in the present study (table-5).

Out of 100 patients of fever with thrombocytopenia, other viral fevers (34\%) was the commonest cause followed by dengue fever (29\%), leptospirosis (13\%), septicemia (13\%), malaria (10\%) and enteric fever (1\%) in the present study. Bleeding manifestation in the form of petechiae was a common manifestation of thrombocytopenia. Petechiae with and without gum bleeding/epistaxis/conjunctival hemorrhage occurred in $16 \%$ of patients in the present study. The gum bleeding alone happened in $1 \%$ of patients, conjunctival hemorrhage alone in $3 \%$ of patients and Malaena in 1\% patients was encountered.

There was no relation between platelet count and bleeding manifestation and maximum number of bleeding episodes occurred when the platelet count was in the range of 20000$40000 /$ cumm. The majority of the patients in our study had total leukocyte count in the range of 2000 to $4000 /$ cumm (40\%) as expected in viral fever (table-6).

Abnormal total bilirubin levels were seen in $26.47 \%$ cases. Abnormal SGOT was seen in $38.24 \%$ and abnormal SGPT was seen in $32.35 \%$ cases in viral fevers.

Dengue fever casesand Leptospirosis cases also showed high or deranged LFT in considerable number of cases (table-7).

\section{DISCUSSION}

The present study included 100 patients of fever with thrombocytopenia in which males were more affected than females; $59 \%$ were males and $41 \%$ were females and the ratio was $1.44: 1$.

\section{Comparative studies based on age distribution}

In the present study, the maximum prevalence of fever with thrombocytopenia was in the age group of 21-30 years with $32 \%$ patients. The least number of patients were in $\geq 60$ year age group with only $2 \%$ accounting for it. In the study by Raiker et $\mathrm{a}^{12}$ they also observed maximum number of cases to be in the age range of 12 - 30 years accounting for $66 \%$ of cases and least prevalence was observed in $>60$ years age group accounting for $10 \%$ of cases. Age distribution in both studies is well correlated. In both the studies maximum prevalence was seen in younger age group and least prevalence was seen in older age group.

\section{Comparative studies based on gender distribution}

In the present study, males were $59(59 \%)$ and females were $41(41 \%)$ and male to female ratio was $1.44: 1$. In a study of fever with thrombocytopenia by Dash et $\mathrm{al}^{13}$ male to female ratio was $1.5: 1$. In Raiker et $\mathrm{l}^{12}$ study this ratio was 2.7:1 and in the study by Lakum $\mathrm{N}$ et $\mathrm{al}^{6}$ it was 1.85:1.

\section{Comparative studies based on clinical signs and symptoms}

In the present study, fever was seen in $100 \%$ of the cases. Other than fever, headache was the most common symptom seen in $32(32 \%)$ cases, followed by myalgias (31\%), vomiting (27\%), pain abdomen (6\%), bleeding manifestations (3\%), and altered sensorium (1\%) cases. In the study by Lakum $\mathrm{N}$ et $\mathrm{al}^{6}$ fever was the presenting complaint in all cases, weakness in $40 \%$ of cases, weight loss in $10 \%$ of cases and bleeding was the presenting complaint in $10 \%$ of cases.

In the present study, most commonly detected signs were splenomegaly (24\%), hepatomegaly (21\%), jaundice (17\%), and petechiae (16\%). Other signs included pallor (7\%) and conjunctival hemorrhage (4\%). In the study by Lakum $\mathrm{N}$ et $\mathrm{al}^{6}$ most common finding was pallor and was seen in $70 \%$ of cases, followed by splenomegaly in $45 \%$ of cases, hepatomegaly in 35\% of cases and lymphadenopathy was seen in $10 \%$ of cases. Table 8 shows comparison of etiology of fever with thrombocytopenia in various studies.

Comparative studies based on platelet count

In ourstudy, platelet count of $\leq 40000 /$ cumm was seen in $20 \%$ of patients and $18 \%$ of patients had platelet count of 40000 $60000 /$ cumm. $27 \%$ patients had platelet count of $60000-$ $80000 /$ cumm and $30 \%$ of patients had platelet count in the range of 80000 to $100000 /$ cumm. In the present study $20 \%$ of patients had platelet count between $20,000-40,000 /$ cumm and $75 \%$ had platelet count above $40,000 /$ cumm. In the study by Dash et $\mathrm{al}^{13}$ majority of patients $(26 \%)$ had platelet count in the range of $61000-80000 / \mathrm{cu} . \mathrm{mm}$, followed by $25 \%$ (21000 - 40000/cu.mm), $19 \%$ in the range of $81000-$ $100000 / \mathrm{cu} . \mathrm{mm}, 17 \%$ of cases in the range of $0-20000 /$ cu.mm, $13 \%$ of cases in the range of $41000-60000 /$ cumm. Results of this study correlate well with the above study. In both the studies, majority of patients were in the range of $61000-80000 /$ cu.mm.

In the study by Raikar et $\mathrm{al}^{12}$ no correlation was seen between the platelet count and bleeding manifestations. In the study by Dash et $\mathrm{al}^{13}$ bleeding manifestations in the form of petechiae and purpura were seen in 35\% of cases and spontaneous bleeding was seen in $18 \%$ of the cases. 


\section{Liver Function Tests in different etiologies}

The total bilirubin level was abnormal in $26.47 \%$ of viral fever cases, $58.62 \%$ of dengue fever cases and $76.92 \%$ of leptospirosis cases and 30\% of malaria cases in the present study. The abnormal SGOT was seen in $38.24 \%$ of viral fever cases, $65.52 \%$ of enteric cases, $84.62 \%$ of leptospirosis and $30 \%$ of malaria cases in the present study. The abnormal SGPT was seen $32.35 \%$ of viral fever cases, $68.97 \%$ of dengue fever cases, $84.62 \%$ of leptospirosis and $20 \%$ of malaria cases in the present study. This shows that abnormal liver function test was more prevalent in leptospirosis and dengue fever because of dengue hepatitis and hepatitis in leptospirosis. Out of 100 cases, 8 cases died. Four deaths were due to septicaemia accounting for $50 \%$ of cases. Two cases died due to dengue shock syndrome contributing to $25 \%$ of deaths, and two cases died due to malaria contributing to $25 \%$ of deaths. In the study by Dash et $\mathrm{al}^{13} 22$ cases died. Septicaemia contributed to $77 \%$ of cases. Dengue contributed to $5 \%$ of cases and malaria contributed to $18 \%$ of cases. So in all the studies septicaemia, dengue, malaria were causes of mortality. In septicaemia, cause of mortality was DIC and multiorgan dysfunction. In Dengue, deaths were due to dengue shock syndrome. In malaria deaths were due to DIC and multiorgan dysfunction.

So strong probability of dengue fever or other common causes like malaria, enteric fever, septicaemia and leptospirosis should be kept in mind in any case of fever and thrombocytopenia to start empirical therapy before final diagnosis is reached so that high mortality can be prevented.

\section{CONCLUSION}

Febrile illness patients should be investigated for platelet count irrespective of the bleeding manifestations. Strong probability of dengue fever or other common causes like viral fever and leptospirosis should be kept in mind in any case of fever and thrombocytopenia as decreased platelet count could be severe without external manifestations and could be an indicator of bad prognosis if not treated early with platelet transfusion.

\section{REFERENCES}

1. Larson EB, Featherstone HJ, Peterfdorf RG. Fever of undetermined origin: Diagnosis and follow up of 105 cases, 1970-1980. Medicine 1982;61(1):269-92.

2. Nolan SM, Fitzgerald FD. Fever of unknown originThe general internist's approach. Postgraduate medicine 1987;81(5):190-205.

3. Woodward TE. The fever pattern as a diagnostic aid. In: Fever: basic mechanisms and management, Mackowiack PA, ed. New York: Lippincott-Raven Publishers;1997. p.215-35.

4. Larsen BE. Fever of unknown origin. Med 1970$80 ; 61(5)$.

5. Bacher KJI. Fever including fever of unknown origin. 13th ed. In: Harrison's Principles of internal medicine. Philadelphia, PA: McGraw-Hill; 1994. p.81-90.

6. Machin SJ. Oxford textbook of Medicine. 3rd ed. p.3630-6.

7. Levine SP. Wintrobe's Clinical Haematology. 10th ed. 1993: 1579-1632.
8. Colman RW, Hirsch J, Marder VJ, Salzman EW. Hemostasis and Thrombosis. Basic principles and clinical practice. 1982. p.246-7.

9. William WJ, Eaenst Beutler E, Erslev AH, Litchman MA. Hematology. 3rd ed. p.1290-342.

10. Firkin F. Degruchy's Clinical haematology in medical practice. 5 th ed. 1990. p.375.

11. George JN, Aizvi MA. Thrombocytopenia. 6th ed. Chapter 117. In: Williams Haematology, Beufler E, ed. New York: McGraw-Hill; 2001.p.1501.

12. Raikar SR, Kamdar PK, Dabhi AS. Clinical and laboratory evaluation of patients with fever with thrombocytopenia. Indian Journal of Clinical Practice 2013;24(4):360-63.

13. Dash HS, Ravikiran P, Swarnlatha. A study of clinical and laboratory profile of fever with thrombocytopenia and its outcome during hospital stay. IJSR 2013; 11(4):445-7.

14. Nair PS, Jain A, Khanduri U, Kumar V. A study of fever associative with Thrombocytopenia. JAPI 2003;51(2):1173.23.

Source of Support: Nil; Conflict of Interest: None

Submitted: 26-12-2019; Accepted: 21-01-2020; Published online: 17-02-2020 